\title{
Comentário
}

\section{Uma interação promissora entre a neurociência básica e a terapêutica em psiquiatria*}

Os conhecimentos acerca do funcionamento íntimo do sistema nervoso central humano, como os diversos mecanismos neurofisiológicos, evoluíram, em grande parte, a partir das observações de pacientes neurológicos e de estudos detalhados post-mortem realizados por neurologistas do passado. Esse foi o caso, por exemplo, do paciente afásico de Paul Broca, neurologista francês que, por meio de estudos clínico-patológicos detalhados do caso, estabeleceu a existência da área da palavra falada no cérebro, que hoje leva o seu nome.

Também se aprendeu muito com terapêuticas experimentais da epilepsia, como no caso das neurocirurgias realizadas por Wilder Penfield, que culminaram no mapeamento detalhado da área motora primária no giro pré-central.

Em 1985, uma nova técnica de estudo da fisiologia cerebral foi colocada à disposição dos neurocientistas, quando se descobriu um campo magnético rapidamente variável no tempo, que, aplicado ao escalpo, era capaz de estimular áreas circunscritas do córtex cerebral. Essa técnica, conhecida como estimulação magnética transcraniana (EMT), foi amplamente utilizada para estudos de mapeamento do córtex motor e pode ser aplicada, de forma totalmente não-invasiva e indolor, no ser humano intacto e desperto.

Depois de fornecer uma série de informações a respeito da fisiologia normal do sistema motor humano, a EMT tem sido investigada atualmente como uma potencial modalidade terapêutica em distúrbios neuropsiquiátricos. Na revisão publicada nesta revista, Chae et al destacam o uso da EMT na depressão refratária aos tratamentos medicamentosos. Os autores colocam em perspectiva, de forma muito apropriada, as aparentes vantagens do método, bem como os pontos duvidosos, como: qual regime de aplicação seria mais eficiente; se o ideal seria a estimulação repetitiva de alta frequiência do córtex pré-frontal esquerdo ou a de baixa frequiência da região homóloga contralateral; e se no futuro essa técnica seria uma opção viável para aqueles pacientes que também podem ser controlados com terapias farmacológicas.

O fato importante, porém, é que a despeito de todas essas incertezas, não pode haver dúvidas de que a EMT poderá contribuir muito para a elucidação de mecanismos neurofisiológicos até agora desconhecidos, e que podem estar na gênese de alguns tipos de depressão ou de outros distúrbios neuropsiquiátricos. Merece destaque a possibilidade de estudar os padrões de alteração metabólica induzidos pela EMT que afetam o humor dos pacientes. Esse estudo pode ser feito com a utilização concomitante de técnicas de imagem, como a ressonância magnética funcional.

A EMT de alta frequiência é capaz de induzir um aumento duradouro da excitabilidade neuronal da região tratada, ao passo que a EMT de baixa freqüência, inversamente, induz uma redução de excitabilidade cortical que perdura por horas ou dias após a aplicação dos estímulos. No caso da depressão, aparentemente, o efeito terapêutico depende de que se produza um aumento da atividade pré-frontal esquerda ou, pelo contrário, uma redução da atividade pré-frontal direita. Os autores citam que o maior estudo já relatado utilizava estimulação pré-frontal direita de baixa freqüência. Outras vantagens da estimulação pré-frontal direita de baixa frequiência não foram mencionadas, exceto a total ausência de relatos na literatura de indução de crises convulsivas em indivíduos não-epilépticos com esse tipo de estimulação. Além disso, entretanto, somam-se outros dados: a estimulação de baixa frequiência não induz aquecimento significativo da bobina, não havendo necessidade de um mecanismo de refrigeração que aumente muito o custo do equipamento; e essa mesma falta de aquecimento da bobina torna nulas as chances de que se produzam queimaduras do escalpo do paciente.

Atualmente há estudos sobre o potencial terapêutico da EMT de baixa freqüência para reduzir a excitabilidade cortical em epilépticos de difícil controle, o que poderia resultar na redução da frequiência das crises.

A estimulação vagal e a estimulação profunda do cérebro são técnicas mais agressivas, porém também consideradas minimamente invasivas pelos autores.

Como no caso da EMT, os mecanismos de ação dessas modalidades terapêuticas nos transtornos neuropsiquiátricos não estão completamente elucidados. Por esse mesmo motivo, entretanto, descortina-se a possibilidade de uma profícua interação entre os ensaios terapêuticos e os estudos de neurociência básica, os quais, certamente, resultarão em significativos avanços para o entendimento de diversos mecanismos neurais, na saúde e na doença.

A revisão de Chae et al é bastante clara, completa e ricamente ilustrada e certamente levará o leitor a apreciar o grande potencial clínico e também científico das técnicas descritas.

Joaquim P Brasil Neto

Laboratório de Neurobiologia da Universidade de Brasília 